\title{
Social Media Disaster Relevance Classification for Situation Awareness during Emergency Response in Indonesia
}

\author{
Risdianto Irawan ${ }^{1}$, Sani M Isa ${ }^{2}$ \\ ${ }^{1}$ Computer Science Department, BINUS Graduate Program - Master of Computer Science, Bina Nusantara \\ University, Jakarta, 11480, Indonesia, risdianto.irawan@binus.ac.id \\ ${ }^{2}$ Computer Science Department, BINUS Graduate Program - Master of Computer Science, Bina Nusantara \\ University, Jakarta, 11480, Indonesia, sani.m.isa@binus.ac.id
}

\begin{abstract}
Natural disasters are expected to increase in number and severity on a global scale. Social media analysis has become an essential tool in natural disaster management on tracking disaster events, impact, and other relevant critical information. However, the high volume of tweets data produces noise, and not all tweets are relevant to gain situational awareness for disaster response. This paper presents a disaster-relevance classification for Indonesian language tweets using machine learning with Naïve Bayes, support vector machine, and logistic regression with a focus on twitter data generated during the Sulawesi Earthquake, Indonesia 2018. With the result accuracy of $83.5 \%$, our labeled data can be used for capturing disaster-relevant tweets in any future disaster event in Indonesia.
\end{abstract}

Key words :Social Media Analysis, Text Mining, Disaster-Relevance Classification, Indonesia

\section{INTRODUCTION}

Every year natural disaster events, such as typhoons, floods, landslides, volcanic eruptions, and earthquakes, cause thousands of death tolls, billions of dollars of property damage, and severe impact on the environment [1]. Indonesia is among the top five risk countries in the Asia Pacific region with a high possibility for the next catastrophic natural disaster. On 28 September 2018, a shallow, M7.5 earthquake hit Sulawesi, Indonesia, with its epicenter located in Donggala Regency, Central Sulawesi. It was followed by a localized tsunami and destroyed many buildings close to the coastal area. The effects of the earthquake and tsunami caused the deaths of an estimated 4,340 people.

In every single disaster event, it is necessary to get information about the damage, impact, and needs as quickly as possible. Government, disaster management authority, and humanitarian actors can act and respond better by knowing what people need, and what is happening in the affected area.

Social media has been used and utilized for many domains, including natural disasters [2] and epidemic disease outbreak [3]. Social media provide information for decision-making and as source information before, during, and after big events, including natural disasters. Twitter, as a social sensor, provides data and key information during a disaster. Twitter users can actively and immediately express their opinion about what they feel in twitter [4]. It allows users to share and express a short message through their tweets about the real situation on and from the affected area during the disaster. In countries with good telecommunications infrastructures such as Indonesia, social media play a significant role as a platform for sharing news and information. For instance, during the Sulawesi Earthquake 2018, hashtag \#gempapalu, \#prayforpalu, and \#prayforindonesia were on the top list of twitter trending topics. It showed that communication and information distribution significantly happened during the Sulawesi Earthquake.

However, twitter data has many noises, and there are many irrelevant tweets for every single event, including natural disasters. Most of the tweets are not useful in providing information about the disaster. During a disaster, we may have a huge number of tweets twitting about the particular disaster but irrelevant, for instance, tweets using the same hashtag for promoting or advertising irrelevant content. Therefore, it is necessary to filter and classify disaster-relevant tweets automatically and accurately to enable quick data-driven decision-making.

Many disaster relevance classification studies have given great contributions to disaster management by resulting and providing disaster lexicon to be used for further research or applied to real disaster management. Related studies on using social media data for disaster analysis mostly performed to classify disaster relevancy for the English language, where the Indonesian language has a different lexicon.

In this paper, we analyzed and labeled tweets manually as disaster-relevant and disaster-irrelevant. The manual labeling was done by disaster practitioners from caribencana.id. The labeled tweets were used as training data on machine learning using several algorithms. The best accuracy model was then used for labeling the other remaining tweets. The following contributions are made in this research: (1) Identify the best machine learning algorithm for classifying disaster relevance for Indonesian language tweets, (2) Identify relevant tweets during disaster response in Indonesia and extract some key information, (3) Provide disaster relevancy tweets data for future research and future disaster event in Indonesia by 
providing open access to the labeled data through ahacentre.org or other open data platforms. In this paper, we present the classification for twitter data generated during Sulawesi Earthquake, Indonesia, 2018.

\section{RELATED WORKS}

There have been several researches on twitter data analysis for disaster monitoring and disaster management. Some researches focused only on typhoon or hurricane disaster-related twitter data. Research on hurricane Matthew, Harvey, and Irma 2017 covering three disaster phases preparedness, response, and recovery, classified tweets based on disaster phase and extract relevant tweets based on location and keywords. The classification used some relevant keywords such as "need", "water", "evacuate", "rescue" and the annotation was done manually. They concluded that logistic regression with uni-gram features gave better accuracy. A proposed framework synthesizing many sources including twitter, remote sensing data, Wikipedia, and other sources used Naïve Byes and logistic regression for classifying the twitter data from Hurricane Sandy 2011 and Colorado flooding 2013 [5][6].

Some researches focused on earthquake data. Carley et al. [2] used geotag and geography boundaries to classify the tweets disaster-related data for early warning system. Ishino et al. [7] evaluating the evacuation route and transportation problem after an earthquake happened. Win et al. [8] used twitter data generated during Myanmar earthquake and classified the tweets into 3 labels: informative, non-informative, and other information. Those research areas address tweets classification and fine-grain category classification during a disaster without identifying the disaster phase. Wang et al. [9] pointed out that most studies with exceptions of Haworth et al. [10] and Yan et al. [11] have focused on disaster response instead of other phases because of lack of data through those phases. Other researches worked on classification of situational-information [12][13]; contextual information to better understanding the situation [14][15]; road-closures and traffic condition during emergency [16] and people sentiment analysis during the emergency [17][18].

The table 1 shows some other related work on twitter data analysis for disaster management, the algorithm, and the language analyzed:

Table 1: Related research on data mining for natural disaster

\begin{tabular}{|l|l|l|l|l|}
\hline No & $\begin{array}{l}\text { Machine learning } \\
\text { classification (yes/no) } \\
\text { and algorithm or } \\
\text { method used }\end{array}$ & $\begin{array}{l}\text { Data } \\
\text { sources }\end{array}$ & $\begin{array}{l}\text { Natural } \\
\text { disaster type } \\
\text { and country }\end{array}$ & $\begin{array}{l}\text { Language } \\
\text { analyzed }\end{array}$ \\
\hline 1 & $\begin{array}{l}\text { No. Text filtering and } \\
\text { analysis[2] }\end{array}$ & Twitter & $\begin{array}{l}\text { Earthquake, } \\
\text { Indonesia }\end{array}$ & $\begin{array}{l}\text { English } \\
\text { Indonesia }\end{array}$ \\
\hline 2 & $\begin{array}{l}\text { Yes. Logistic } \\
\text { regression, support } \\
\text { vector machine, Naïve } \\
\text { Bayes and Stanford } \\
\text { classifier [19] }\end{array}$ & Twitter & $\begin{array}{l}\text { Hurricane, } \\
\text { USA }\end{array}$ & English \\
\hline
\end{tabular}

\begin{tabular}{|c|c|c|c|c|}
\hline 3 & $\begin{array}{l}\text { Yes. Naïve Bayes, } \\
\text { latent Dirichlet } \\
\text { allocation (LDA) and } \\
\text { logistic regression [5] }\end{array}$ & $\begin{array}{l}\text { Twitter, } \\
\text { Wikipedi } \\
\text { a, } \\
\text { satellite } \\
\text { data }\end{array}$ & $\begin{array}{l}\text { Hurricane, } \\
\text { USA }\end{array}$ & English \\
\hline 4 & $\begin{array}{l}\text { Yes. support vector } \\
\text { machine (SVM ), KNN } \\
\text { methodology and } \\
\text { naïve Bayes [20] }\end{array}$ & Twitter & Flood, India & English \\
\hline 5 & $\begin{array}{l}\text { Yes. LibLinier classifier } \\
\text { [8] }\end{array}$ & Twitter & $\begin{array}{l}\text { Earthquake, } \\
\text { Myanmar }\end{array}$ & English \\
\hline 6 & $\begin{array}{l}\text { No. Time series, text } \\
\text { processing [21] }\end{array}$ & Twitter & $\begin{array}{l}\text { Earthquake, } \\
\text { Japan }\end{array}$ & English \\
\hline 7 & No. Text mining [22] & Twitter & $\begin{array}{l}\text { Flood, } \\
\text { Australia }\end{array}$ & English \\
\hline 8 & $\begin{array}{l}\text { Yes. Text mining, } \\
\text { latent semantic } \\
\text { analysis (LSA), time } \\
\text { series [23] }\end{array}$ & $\begin{array}{l}\text { Blog and } \\
\text { Twitter }\end{array}$ & $\begin{array}{l}\text { Earthquake, } \\
\text { Japan }\end{array}$ & English \\
\hline 9 & $\begin{array}{l}\text { No. Text processing } \\
\text { [24] }\end{array}$ & Twitter & Flood, USA & English \\
\hline 10 & $\begin{array}{l}\text { No. Text filtering and } \\
\text { analysis[25] }\end{array}$ & Twitter & $\begin{array}{l}\text { Earthquake } \\
\text { and tsunami, } \\
\text { Indonesia }\end{array}$ & $\begin{array}{l}\text { English, } \\
\text { Indonesia }\end{array}$ \\
\hline
\end{tabular}

From the above table we found most of relevancy classification researches are specific for the English language. Some researches are analyzing twitter in Indonesian language using keyword filtering without relevancy classification. Therefore, we propose machine learning approach for disaster-relevancy classification on this paper.

\section{METHODOLOGY}

\subsection{Data Collection}

We used sample data from past disaster events, Sulawesi Earthquake, Indonesia, 2018. However, the result of this classification research can be used for any future disaster event in Indonesia. The historical tweets data we got from twitter API with below parameters:

- Tweet time: 28 September 2018 - 28 October 2018

- Keywords: Gempa, Likuifaksi, Tsunami, Sunami (Indonesian language for earthquake, liquefaction, and tsunami) and Palu, Donggala, Sigi, Petobo, Sulawesi, Sulteng, Sigi (some areas were strongly affected by the earthquake and tsunami).

We collected a total of $1,718,499$ tweets with those given parameters. To refine the data, we filtered the tweets with the combinations "event AND area" i.e.: (gempa OR likuifaksi OR tsunami OR sunami) AND (palu OR donggala OR sigi OR sulawesi OR sulteng OR sigi). Then, we removed the retweet. The number of data was significantly reduced to only 137,319 tweets. 


\subsection{Data labeling for disaster relevancy}

For this purpose, we randomly selected 3,600 data to be labeled manually as relevant or irrelevant. The manual label was done by disaster practitioners from caribencana.id ${ }^{1}$. Table 2 shows the manual label tweets classification.

Table 2:Manual tweets classification

\begin{tabular}{|c|c|c|}
\hline Tweets & Relevant & Irrelevant \\
\hline 3,600 & 1,855 & 1,745 \\
\hline
\end{tabular}

Some irrelevant tweets included hope, prayer, condolence sentences such as: "Ya Allah, lindungilahsaudara kami disana... (in English: God, please protect our brothers there"; "Semogadikuatkanbagisemua korban gempa... (in English: Hopefully, all the victim stay strong ...". Figure 1 shows irrelevant tweets captured from twitter.
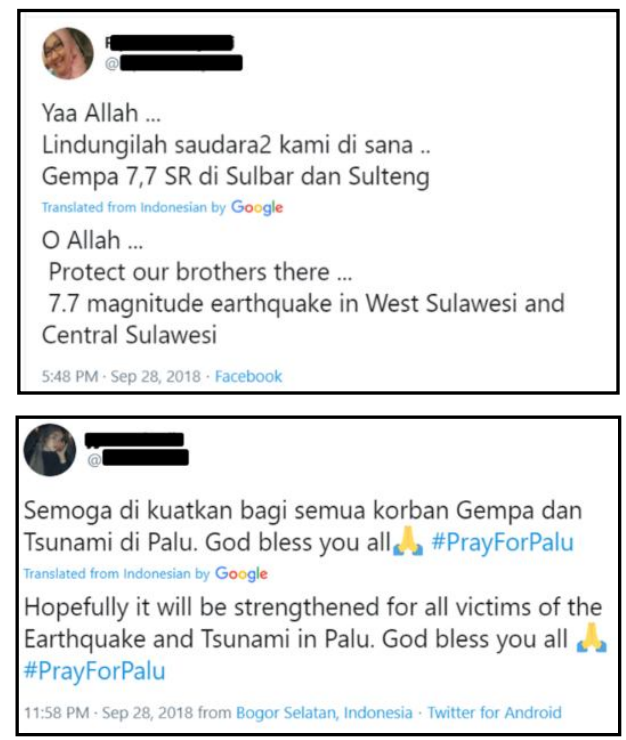

Figure 1: Irrelevant tweets captured from twitter

We found also many irrelevant tweets mentioned about country political issues while the next coming year was Indonesia presidential election. We labeled tweet contains information about ground situation, number of affected people, relief items, shelter, earthquake information, early warning, delivery of donation, damage building, or evacuation process as relevant. Figure 2 shows relevant tweets captured from twitter.

${ }^{1}$ CARI (https://caribencana.id) is a spatial-based portal that provides risk \& resilience analytics and insights based on scientifically proven and published research.
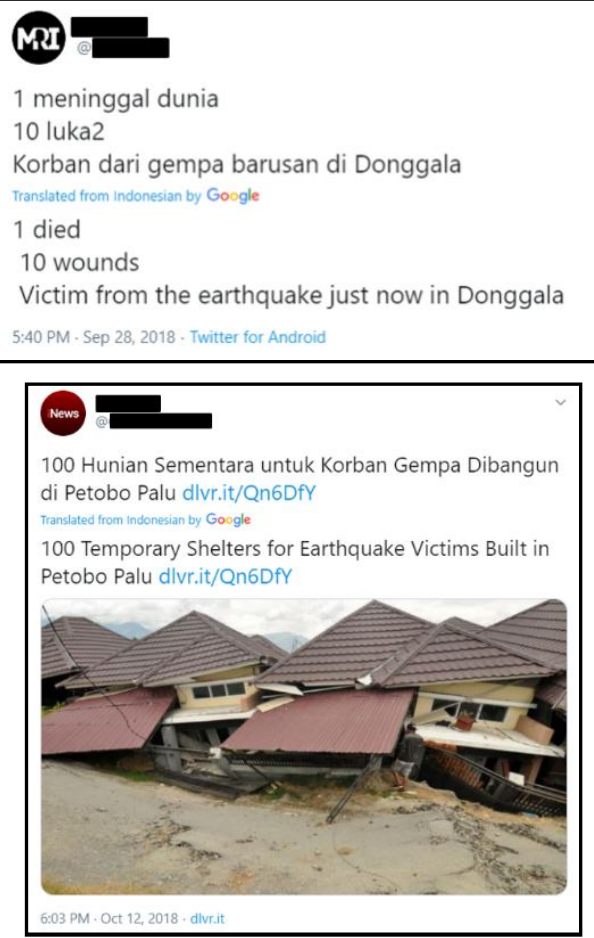

Figure 2: Relevant tweets captured from twitter

\subsection{Tweets Preprocessing}

Tweet text preprocessing is needed to train the machine learning better about the text classification. We used Azure Machine Learning Studio for text preprocessing, including removing stop-words, normalizing case to lowercase, removing numbers, removing special characters, removing email addresses and URLs, normalizing backslashes to slashes, and split tokes on special characters. Particularly for stop-words, we used vocabulary from NLTK library in the Indonesian language such as "ada", "adalah", "yang", "di", "dan", "sebuah", "ke", .etc.

\subsection{Data classification}

Based on related works and researches, some methods give the best results for relevance classification for tweets, i.e., Naïve Bayes, support vector machine (SVM), and logistic regression. Those three algorithms were also used in this research with some parameter tuning to find the best accuracy.

The advantage of using text annotation and machine learning, we can train and build the model to annotate vast numbers of cases using relatively small amounts of manually annotated training data accurately and reliably [26][27].

We used the Azure Machine Learning platform to build the machine learning classification model. Feature hashing was used to convert text data to integer encoded features using the Vowpal Wabbit library Feature hashing convert unique tokens into integers. It runs on the exact strings as input and does not perform any linguistic analysis or preprocessing. We used 17 hashing bitsize and $12 \mathrm{~N}$-grams. 
The data was split into 70:30 for the train model and score model using three algorithms Naïve Bayes, linear Support Vector Machine, and logistic regression. We evaluated each model using confusion matrix to get accuracy, precision, and F1 score. We applied the best model with the highest accuracy and F1 score to classify the rest of the tweet data.

\subsection{Key Information Extraction}

To be able to better understand the situation, we analyzed the tweets with time series analysis to see how was disaster relevance tweets from day 1 to day 30 of the disaster. We analyzed who tweeted more disaster-relevant tweets by counting the tweets for each user. We also visualized the geotagged tweets on the map to see where the relevant and irrelevant tweets came from.

\section{RESULTS}

The classification model using Naïve Bayes, SVM, and Logistic regression, and resulted the same F1 score where the two-class logistic regression as the best model with the highest accuracy, precision. Figure 3, 4 and 5 show AUC graph and confusion matrix for each classification model Naïve Bayes, SVM, and Logistic regression

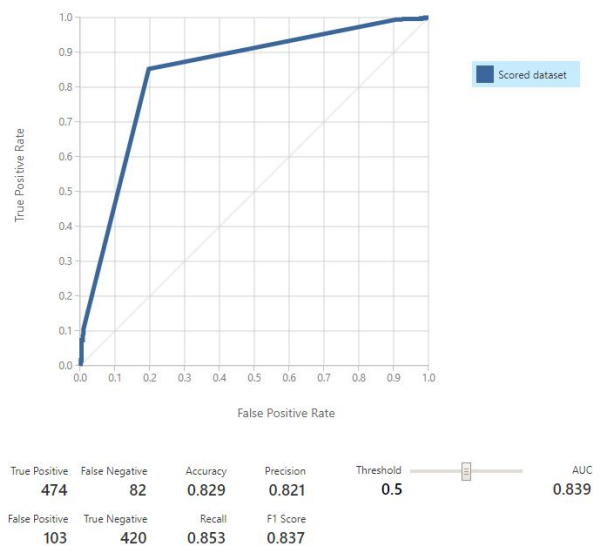

Figure 3: AUC graph and confusion matrix result using Naïve Bayes

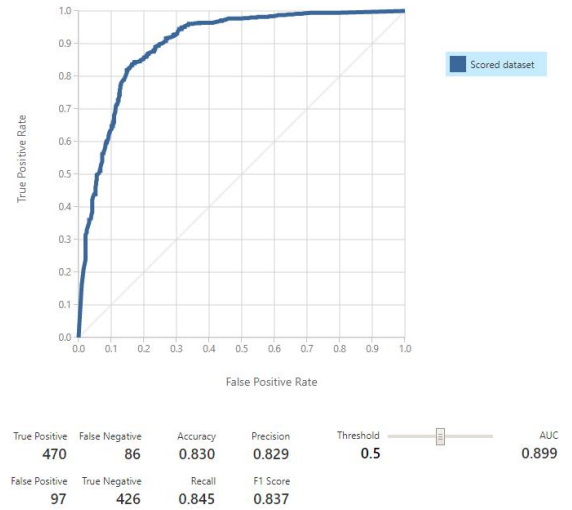

Figure 4: AUC graph and confusion matrix result using SVM

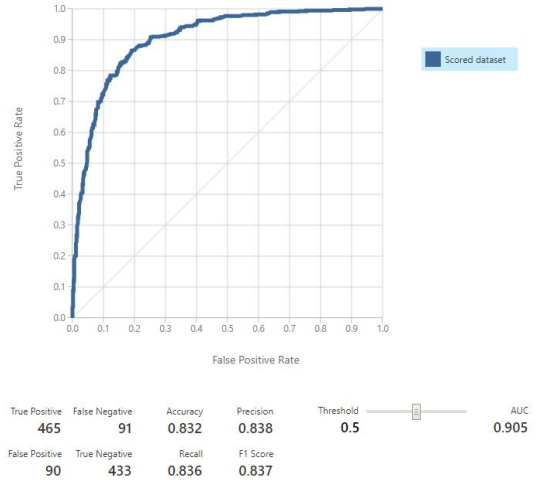

Figure 5: AUC graph and confusion matrix result using Logistic Regression Table 3: Model Score Comparison

\begin{tabular}{|c|c|c|c|}
\hline Algorithm & Accuracy & Precision & F1 Score \\
\hline Naïve Bayes & 0.829 & 0.821 & 0.837 \\
\hline SVM & 0.830 & 0.829 & 0.837 \\
\hline Logistic Regression & 0.832 & 0.838 & 0.837 \\
\hline
\end{tabular}

By using the best algorithm, Logistic Regression, figure 6 shows all data was classified for relevant (labeled as 1) and irrelevant (labeled as 0) using Azure Machine Learning Studio.

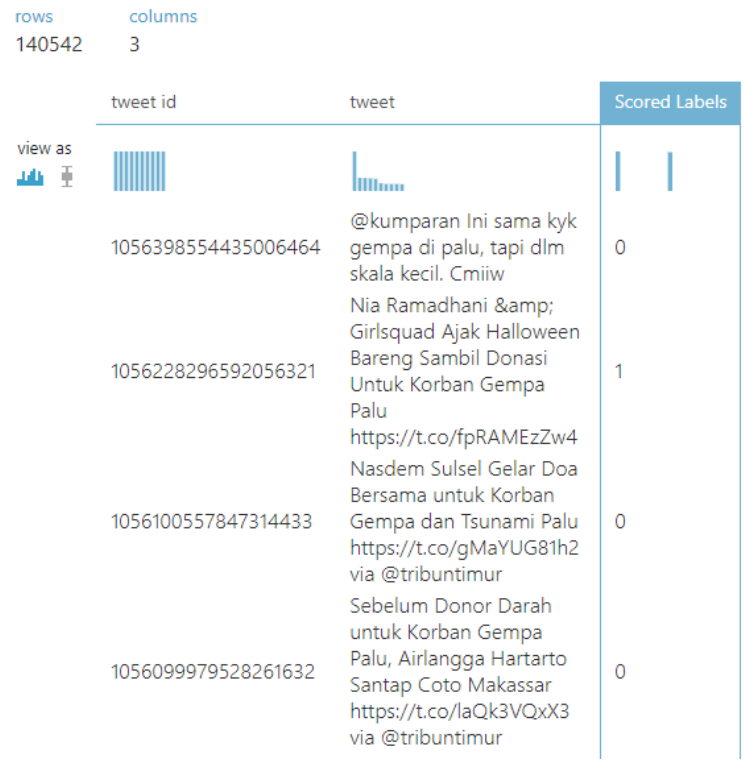

Figure 6: Classification result in the Microsoft Azure ML Studio for the remaining dataset

Table 4 shows an almost equal number of relevant and irrelevant data:

Table 4: Model Score Comparison

\begin{tabular}{|c|c|c|}
\hline Classification & Rows & $\begin{array}{c}\text { The percentage from } \\
\text { the cleaned dataset }\end{array}$ \\
\hline Relevant & 69,585 & $49.51 \%$ \\
\hline Irrelevant & 70,956 & $50.49 \%$ \\
\hline
\end{tabular}


The total relevant data 69,585 is minimal compare with the whole dataset; it is only $4.05 \%$ of the entire dataset $1,718,499$. Meaning that there is just view relevant tweets during the disaster. However, 69,585 is a considerable number to get information about situational awareness about the disaster on the ground. This model can be used for future disasters, particularly in Indonesia to better clean the twitter from the noise and get better information for data-driven decision making by the disaster management agency.

The graph below shows that during the first six days of Palu Earthquake, there were many irrelevant tweets compare with relevant tweets. That was because there were many condolences, hope, and prayer tweets during that first week.

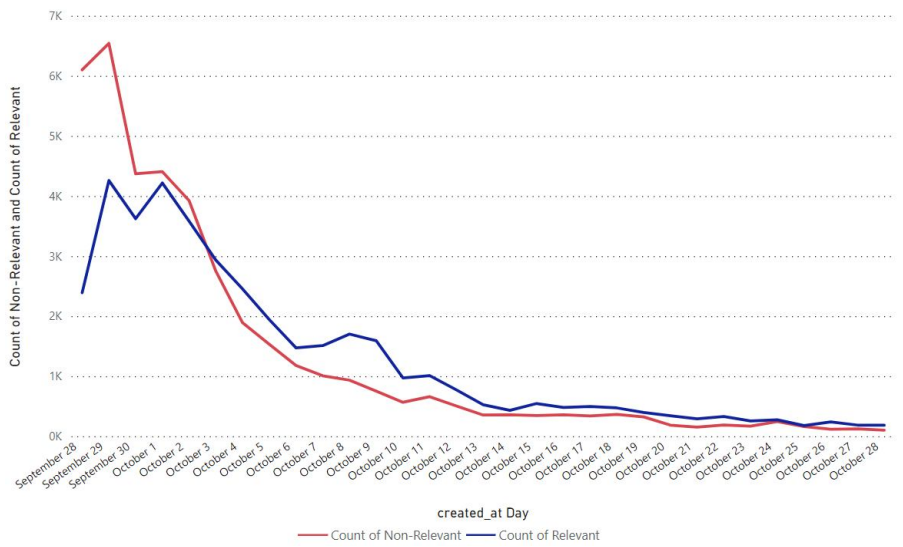

Figure 7: Irrelevant vs. relevant tweets time series

We found that 54,858 tweets have geotagged coordinate. We then analyzed by visualizing the distribution of the tweets using heat-map. Most of the tweets came from Indonesia. Figure 8 and figure 9 below show irrelevant and relevant tweet distribution, where many irrelevant tweets were coming from outside Indonesia compare with its relevant tweets. Indonesian people were living abroad, tweeted more about condolences and prayer.

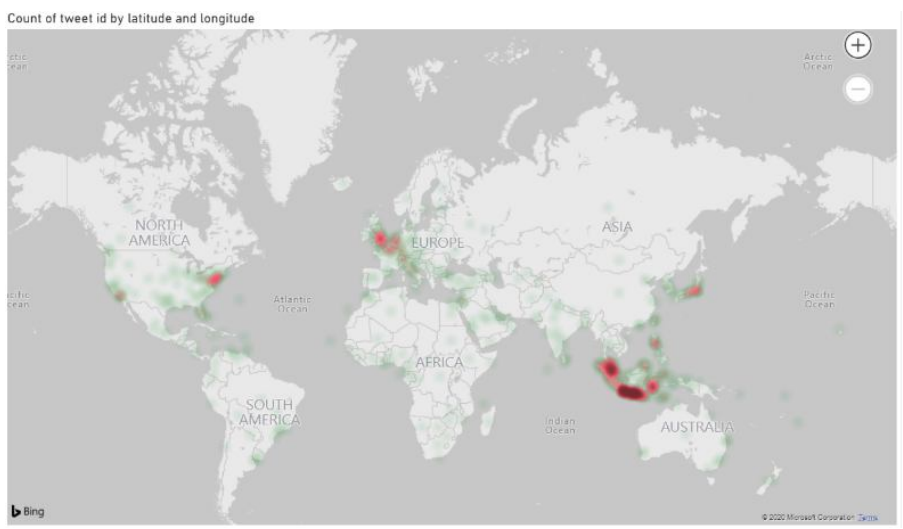

Figure 8: Irrelevant tweets distribution map (lowest:light-green to highest:dark-red)

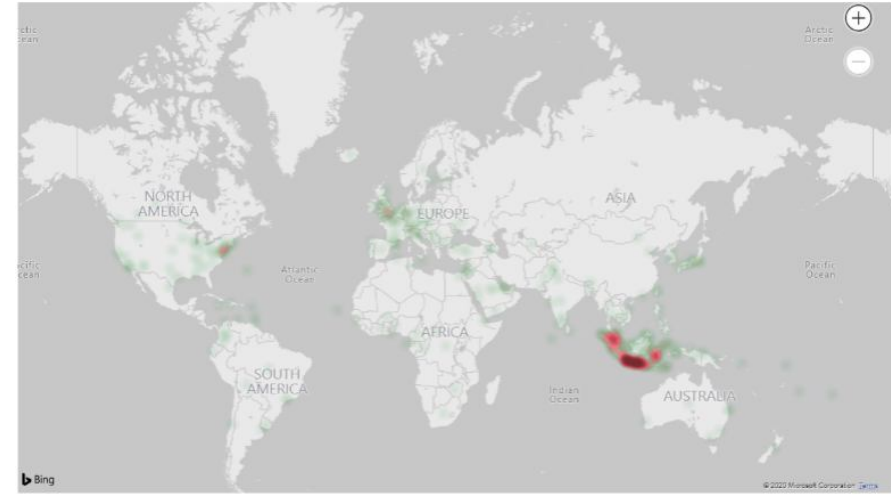

Figure 9: Relevant tweets distribution map (lowest:light-green to highest:dark-red)

We analyzed where the relevant tweets came from. We found the relevant tweets were mostly tweeted by local news agency account such as: liputan6dotcom, horassumutnews, kumparan, merdekadotcom, etc. as shown in figure 10 below:

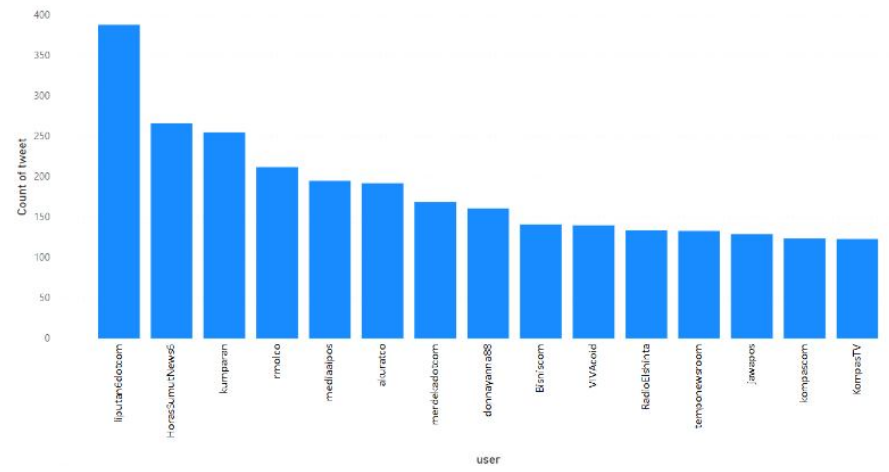

Figure 10: Relevant tweets count by user

From the relevant tweets, we found that gempa (in English: earthquake), palu and donggala (most affected area), korban (in English: casualties), likuifaksi (in English: liquefaction) and tsunami are among the most tweeted words. Figure 11 shows relevant tweets word cloud.

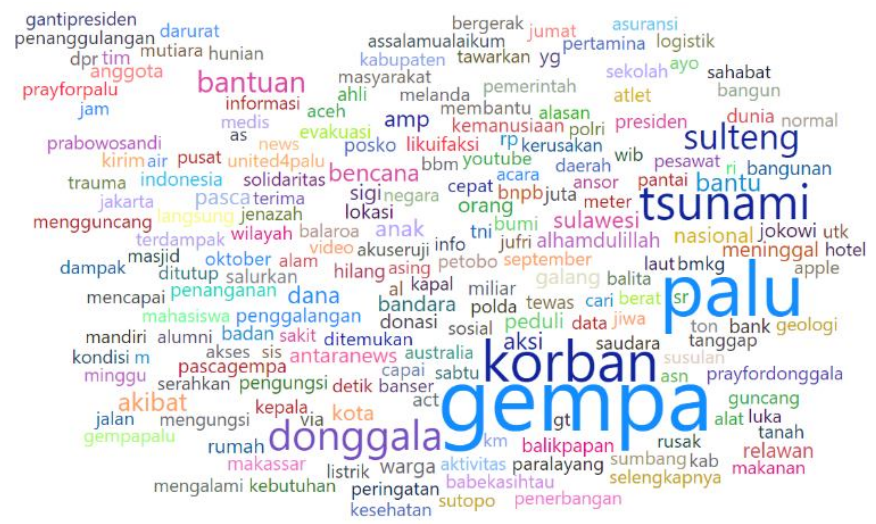

Figure 11: Relevant tweets word cloud

Other essential words related important for disaster management among the mist tweeted words are pengungsi (in English: displaced people), bandara (in English: airport), 
bantuan (in English: donation), evakuasi (evacuation), etc. Some humanitarian actor were also captured, including BNPB (Indonesia National Disaster Management Authority), Sutopo (BNPB's spoke person), ACT (AksiCepatTanggap, a non-government humanitarian organization).

\section{CONCLUSION AND FUTURE WORK}

In this paper we analyzed three algorithms of text classification using machine learning and found that logistic regression provided the best result accuracy $83.2 \%$. The number of relevant tweets is only $4.05 \%$ of the entire dataset, showing that there are many noises in tweets data and relevance classification is definitely needed to classify the relevant tweets to get better understanding about the situation on disaster response.

Our work is limited in scope to classify relevant and irrelevant tweets in Indonesian language. However, there are more information we need to extract to get situational awareness during disaster response including assistance needs, relief items needs, phase of disaster and entity recognition.

\section{ACKNOWLEDGEMENT}

Data on this work is supported by the ASEAN Coordinating Centre for Humanitarian Assistance on disaster management (AHA Centre)

\section{REFERENCES}

[1] P. Velev, D. andZlateva.Use of social media in natural disaster management, Internatonal Proceeedings ofEconomic Dev. Res., pp. 39,41-45., 2012.

[2] K. M. Carley, M. Malik, P. M. Landwehr, J. Pfeffer, and M. Kowalchuck.Crowd sourcing disaster management: The complex nature of Twitter usage in Padang Indonesia, Saf. Sci., vol. 90, pp. 48-61, 2016. https://doi.org/10.1016/j.ssci.2016.04.002

[3] S. R. Kumar, M. V. Krishna, and Anurag. A survey on prediction approaches for epidemic disease outbreaks based on social media data, International Journal of Advanced Trends in Computer Science and Engineering, vol. 8, no. 3, 2019. https://doi.org/10.30534/ijatcse/2019/86832019

[4] E. K. Andana, M. Othman, and R. Ibrahim. Comparative Analysis of Text Classification Using Naive Bayes and Support Vector Machine in Detecting Negative Content in Indonesian Twitter, International Journal of Advanced Trends in Computer Science and Engineering, vol. 8, no. 1.3, 2019. https://doi.org/10.30534/ijatcse/2019/6481.32019

[5] Q. Huang, G. Cervone, and G. Zhang.A cloud-enabled automatic disaster analysis system of multi-sourced data streams: An example synthesizing social media, remote sensing and Wikipedia data, Comput. Environ. Urban Syst., vol. 66, pp. 23-37, 2017. https://doi.org/10.1016/j.compenvurbsys.2017.06.004

[6] K. Stowe, J. Anderson, M. Palmer, L. Palen, and K. Anderson. Improving Classification of Twitter Behavior During Hurricane Events,6th Int. Work.
Nat. Lang. Process. Soc. Media, pp. 67-75, 2018.

[7] A. Ishino, S. Odawara, H. Nanba, and T. Takezawa. Extracting Transportation Information and Traffic Problems from Tweets during a Disaster, Proc. IMMM, pp. 91-96, 2012.

[8] S. S. M. Win and T. N. Aung.Target oriented tweets monitoring system during natural disasters, 16th IEEE/ACIS Int. Conf., pp. 143-148, 2017. https://doi.org/10.1109/ICIS.2017.7959984

[9] X. Wang, Z., Ye.Social media analytics for natural disaster management, Int. J. Geogr. Inf. Sci. 32(1), pp. 49-72,2018. https://doi.org/10.1080/13658816.2017.1367003

[10] P. Haworth, B., Bruce, E., Middleton. Emerging technologies for risk reduction: assessing the potential use of social media and VGI for increasing community engagement, Aust. J. Emerg. Manag 30(3), p. 36, 2015.

[11] A. Yan, Y., Eckle, M., Kuo, C.L., Herfort, B., Fan, H., Zipf. Monitoring and assessing post disaster tourism recovery using geotagged social media data, ISPRS Int. J. Geo-Inf. 6(5), p. 144, 2017. https://doi.org/10.3390/ijgi6050144

[12] C. Zhang et al. GeoBurst: Real-Time Local Event Detection in Geo-Tagged Tweet Streams, ACM Trans. Intell. Syst. Technol., vol. 9, no. 3, pp. 1-24, 2018. https://doi.org/10.1145/2911451.2911519

[13] A. Shaw, F., Burgess, J., Crawford, K., and Bruns.Sharing news, making sense, saying thanks: Patterns of talk on Twitter during the Queensland floods, Aust. J. Commun., 2013.

[14] D. H.-L. Sreenivasan, N. D., Lee, C. S., and Goh.Tweet me home: exploring information use on Twitter in crisis situations, Online Communities Soc. Comput., 2011. https://doi.org/10.1007/978-3-642-21796-8_13

[15] F. D. and S. V. A. Olteanu, C. Castillo. CrisisLex: A Lexicon for Collecting and Filtering Microblogged Communications in Crises, Assoc. Adv. Artif. Intell., 2014.

[16] S. Truelove, M., Vasardani, M., and Winter.Towards credibility of micro-blogs: characterising witness accounts, GeoJournal, pp. 1-21, 2014. https://doi.org/10.1007/s10708-014-9556-8

[17] Q. Huang and C. Xu.A data-driven framework for archiving and exploring social media data, Ann. GIS, vol. 20, no. 4, pp. 265-277, 2014. https://doi.org/10.1080/19475683.2014.942697

[18] J. R. Ragini, P. M. R. Anand, and V. Bhaskar. Big data analytics for disaster response and recovery through sentiment analysis, Int. J. Inf. Manage., vol. 42, no. May, pp. 13-24, 2018. https://doi.org/10.1016/j.ijinfomgt.2018.05.004

[19] A. A. Khaleq and I. Ra.Twitter analytics for disaster relevance and disaster phase discovery. In Proceedings of the Future Technologies Conference, pp. 401-417. Springer, Cham, 2018. https://doi.org/10.1007/978-3-030-02686-8_3

[20] M. MadhuBala.Text Mining On Real Time Twitter, Int. J. Civ. Eng. Technol., vol. 8, no. May 2017, pp. 20-29, 2017. 
[21] T. Sakaki, M. Okazaki, and Y. Matsuo. Earthquake Shakes Twitter Users: Real-time Event Detection by Social Sensors, Proc. 19th Int. Conf. World wide web 10, p. 851, 2010.

[22] F. Cheong and C. Cheong.Social Media Data Mining A Social Network Analysis Of Tweets During The 2010-2011 Australian Floods, Pacific Asia Conf. Inf. Syst., no. July, pp. 1-16, 2011.

[23] T. Hashimoto, B. Chakraborty, T. Kuboyama, and Y. Shirota. Temporal awareness of needs after east japan great earthquake using latent semantic analysis, Information Modelling and Knowledge Bases $X X V, 25$, p.200. 2014.

[24] H. Dong, M. Halem, and S. Zhou.Social Media Data Analytics Applied to Hurricane Sandy,International Conference on Social Computing, pp. 963-966.

[25] A. T. Chatfield and U. Brajawidagda.Twitter Early Tsunami Warning System: A Case Study in Indonesia's Natural Disaster Management, 46th Hawaii International Conference on System Sciences, pp. 2050-2060, 2013 https://doi.org/10.1109/HICSS.2013.579

[26] C. C. and J. Wilkerson. Introduction: Text Annotation for Political Science Research, J. Inf. Technol. Polit., 2008. https://doi.org/10.1080/19331680802149590

[27] A. Olteanu, C. Castillo, and N. Diakopoulos. Comparing Events Coverage in Online News and Social Media: The Case of Climate Change, Proc. AAAI Conf. Web Soc. Media (ICWSM'15). AAAI Press. Oxford, UK., 2015. 